\title{
CONDENSAÇÃO A SUPERFÍCIE NA AMAZÔNIA EM ÁREA DE PASTAGEM DURANTE O EXPERIMENTO LBA/SMOCC: ESTUDO DE CASOS.
}

\author{
ANTONIO MARCOS DELFINO DE ANDRADE E MARCOS ANTONIO LIMA MOURA \\ Universidade Federal de Alagoas - UFAL, Maceió - Alagoas, Brasil. \\ marcoslaba@hotmail.com,malm@ccen.ufal.br \\ Recebido Julho 2010 - Aceito Dezembro 2010
}

\begin{abstract}
RESUMO
A condensação é uma variável indispensável para o entendimento de muitos processos hidrológicos e biológicos, os quais estão envolvidos em uma grande variedade de processos naturais que atuam em diferentes escalas espaciais e temporais. Na Amazônia é comum se observar tal fenômeno durante a madrugada, principalmente na época seca. Dentro da estrutura do experimento Large Scale Biosphere-Atmosphere Experiment in Amazonia (LBA), a campanha Smoke, Aerosols, Clouds, Rainfall, and Climate (SMOCC) foi realizada no período de setembro a novembro de 2002 no antigo sítio experimental do projeto ABRACOS, Rondônia, onde foi possível fazer detalhadas medições das propriedades químicas e físicas da atmosfera, dentre outros, a formação e dissipação da condensação do vapor d'água à superfície. De acordo com resultados obtidos, a formação da condensação ocorreu durante o período noturno por apresentar condições propícias para seu acontecimento. Para os eventos analisados nesse trabalho, foi observado que sua formação e manutenção ocorrem em função da intensidade do vento. Contudo, é possível argumentar que a calmaria é fator determinante para o surgimento da condensação.
\end{abstract}

palavras-chave: condensação de vapor d'água e variáveis meteorológicas.

\begin{abstract}
SURFACE CONDENSATION IN THE AMAZON FROM THE PASTURE AREA DURING LBA/SMOCC EXPERIMENT: CASE STUDIES.

The condensation is an indispensable variable to the knowledge of some hydrologic and biologic process which is involved in a great natural process variety, which acts in different space and secular scales. In the Amazon is common to see such phenomenon on the dawn period, mainly in dry times. Inside the structure of Large Scale Biosphere-Atmosphere Experiment in Amazonia (LBA), the Smoke, Aerosols, Clouds, Rainfall and Climate (SMOCC) campaign was realized in a period between September and November 2002, on the old ABRACOS's small experimental farm, located in Rondônia, where was possible to make detailed measurements from of the chemical and physical properties of the atmosphere, the formation and waste of water vapor's surface. According to the results, the condensation formation occurred during nocturnal period for presenting propitious conditions for its event. To the events analyzed in this work, it was observed that its formation and maintenance had been in function of the wind intensity. However, it is possible to argue that the calmness is a determinative factor for the condensation sprouting.
\end{abstract}

Keys-words: water vapor's condensation and meteorological variables. 


\section{INTRODUÇÃO}

Este trabalho tem como objetivo estudar a formação e dissipação da condensação do vapor d'água à superfície em área de pastagem durante o período de transição seco-chuvoso, dentro da estrutura do experimento Large Scale Biosphere-Atmosphere Experiment in Amazonia (LBA). A campanha Smoke, Aerosols, Clouds, Rainfall and Climate (SMOCC) foi realizada no período de setembro a novembro de 2002 no antigo sítio experimental do projeto ABRACOS, no Estado de Rondônia.

A floresta Amazônica é uma das principais fontes de aquecimento da atmosfera terrestre, e uma importante fonte de energia e umidade para os processos que ocorrem na atmosfera tropical. Sendo uma floresta equatorial de clima quente e úmido, a floresta Amazônica possui uma alta pluviosidade (valores médios de precipitação anual entre 2.000 a $2.200 \mathrm{~mm}$ ) associada a uma forte atividade convectiva com períodos longos e intensos de chuvas durante o ano.

As transformações de florestas em pastagens alteram as interações entre o sistema solo-planta-atmosfera, causando alteração dos ciclos de água e de participação de energia solar. Dias e Regnier (1996) mencionam que regiões desmatadas podem produzir anomalias com impacto importante nos transportes de energia e de água. Cutrim et al. (1995) mostram que estes transportes podem dar origem a nuvens cúmulus sobre regiões de transição entre vegetações distintas. As pastagens causam o aumento do albedo, diminuição da rugosidade da superfície, redução do índice de área foliar (e associada interceptação do dossel) e da umidade do solo (Gash e Nobre 1997).

A condensação é uma variável indispensável para o entendimento do ciclo hidrológico, o qual está relacionado com uma grande variedade de processos naturais que atuam em diferentes escalas espaciais e temporais. Esse parâmetro climático importante nas florestas é chamado de "precipitação oculta". Na Amazônia é comum se observar tal fenômeno durante a madrugada, principalmente na época seca. A probabilidade de formação de nevoeiro noturno pode ser estimada a partir da relação entre o tempo de formação e o comprimento da noite.

Martins (1999) comentou que na fase inicial do processo de condensação, em um movimento uniformemente ascendente da parcela de ar, este é caracterizado por valores crescentes tanto da supersaturação, quanto da concentração de núcleos de condensação ativados. O mesmo autor afirma que esse processo envolve duas equações: (1) fornece o crescimento individual de cada núcleo de condensação, a partir da difusão de vapor d'água e calor, em termos da supersaturação do meio em torno da gotícula; (2) fornece a taxa de variação da supersaturação no meio. A difusão de vapor d'água e calor são os processos que determinam o crescimento da gotícula em sua fase inicial de crescimento por condensação.

Segundo Artaxo et al. (2006), partículas de aerossóis em suspensão na atmosfera influenciam fortemente o balanço radiativo e químico da atmosfera e o clima, visibilidade, e a saúde das pessoas expostas às altas concentrações de partículas, desde a escala local até as escalas regional e global. A condensação ocorre sobre pequenas partículas em suspensão na atmosfera, as quais são conhecidas como núcleos de condensação. A condensação em certos núcleos ocorre com tensões de vapor inferiores à tensão de saturação para uma superfície plana de água pura à mesma temperatura. Alguns núcleos de condensação, tais como os núcleos salinos, denominados higroscópicos, apresentam uma forte tendência para absorver a água, o que favorece a condensação (Artaxo et al. 2006).

\section{MATERIAL E MÉTODOS}

\subsection{Descrição da área de estudo}

O experimento LBA-SMOCC (Large Scala BiosphereAtmosphere - Smoke, Aerosols, Clouds, Rainfall and Climate) foi realizado na Fazenda Nossa Senhora Aparecida $\left(10^{\circ}\right.$ 45'44'S, 62 21'27' W, 315 m) no Estado de Rondônia, sudoeste da Amazônia, Brasil, no mesmo sítio do projeto ABRACOS. A vegetação predominante na área de estudo é o capim (Brachiaria Brizantha), mas encontraram-se também palmas e arbustos isolados. O local é utilizado como uma fazenda de gado, onde a pastagem é bastante plana, cercada por uma série de pequenas colinas (300-440m de altura), em distâncias de 3 a $4 \mathrm{~km}$. O sitio foi escolhido, por ser considerado como representante da região no sudoeste da Amazônia com extensa queima de biomassa durante a estação seca. Mais detalhes sobre a descrição do sitio pode ser encontrado em Andreae et al. (2002) e Trebs et al. (2004).

\subsection{Climatologia da região}

A climatologia local foi descrito por Trebs et al. (2004), apresentando pequenas variações na temperatura do ar no fim da estação seca (Junho/Julho), e durante o período de transição seco-chuvoso (setembro/outubro), oscilando entre $25-26{ }^{\circ} \mathrm{C}$. Os valores anuais da umidade relativa do ar são elevados, com médias de aproximadamente $70 \%$ na estação seca e $80 \%$ durante a estação úmida. As velocidades de vento predominantes são relativamente baixas (média diária 1,5 m $\mathrm{s}^{-1}$ ) com mínimo durante o período noturno. A precipitação nesta região mostra um ciclo sazonal com valores mais baixos em julho, sendo mais elevada de novembro a abril (até $300 \mathrm{~mm} \mathrm{mês}^{-1}$ ) (Andreae et al. 2002). Uma descrição 
detalhada do histórico do local pode ser encontrada em Kirkman et al. (2002) e Ferreira da Costa et al. (1998).

\subsection{Período de estudo}

As medições foram conduzidas no período de 16 de setembro a 12 de novembro de 2002. O desenvolvimento do experimento abrangeu o período de transição da estação secachuvosa (setembro a outubro), e estendeu-se até o início da chuvosa nesta parte de Amazônia (novembro). Em 2002, o tempo típico da estação seca durou até a primeira semana de outubro, sendo caracterizado por episódios intermitentes de precipitação e dias secos. Para a mesma região, Santos (2005) dividiu este período em duas etapas, seco e chuvoso, a partir do dia 12 até 30 de setembro foi considerado período seco e $1^{\circ}$ de outubro a 12 de novembro período chuvoso.

\subsection{Variáveis mensuradas}

Foi montada uma estação meteorológica automática (EMA), que realizou medidas a cada 10 segundos, as quais foram armazenadas a cada minuto. A EMA foi constituída pelos seguintes equipamentos: Temperatura e umidade do ar (HMP35C) - instalados a 0.5 e 5.0 metros de altura. Saldo de radiação (NR-Lite) - mede o balanço da radiação solar ou radiação líquida e estava instalado a 2 metros de altura. Velocidade de vento (03001-5 R. M. Young) - foram também instalados a uma altura de 0.5 e 5.0 metros. Perfil de temperatura do solo (Termopar tipo E) - o sensor utilizado foi o termopar de cobre - constantan e foram instalados no seguinte perfil: $0.01,0.025,0.05,0.10,0.20,0.40$ e 0.60 metros. Para este estudo só foi utilizado o valor a $0,01 \mathrm{~m}$. Precipitação (TE 525) - Instrumentos do tipo báscula e foi instalado a 1 metro. Condensação do vapor d'água atmosférico (WSG237) - Foram utilizados dois sensores WSG237 montados próximos a superfície. Um sensor junto ao solo, ou seja, dentro das folhagens (WSG237_1) e outro sobre as folhagens (WSG237_2). Este instrumento consiste em uma placa de circuito rígido $(75 \times 60 \mathrm{~mm}) \mathrm{com}$ os filamentos de cobre folheado a ouro. O sensor é composto de um circuito flexível de película de poliamida $(14$ x $90 \mathrm{~mm})$, também com filamentos de cobre folheado a ouro. O princípio de funcionamento do WSG é detectar vapor d'água na atmosfera pela resistência, que é medida em ohms $(\Omega)$, quando ocorre condensação sobre o mesmo há uma queda de resistências. Quando o sensor WSG marca um valor igual a 6999, significa que está completamente seco. Esses equipamentos foram adquiridos da Campbell Scientific, dos Estados Unidos da América (EUA), exceto o de Precipitação que foi adquirido da Texas Instruments, EUA.

\subsection{Tratamento dos dados}

A partir dos registros médios a cada minuto foram calculadas as médias horárias, verificada a consistência dos dados e construídos os gráficos com o recurso computacional adequado. Salienta-se que foram eliminadas medidas do WSG nos horários de chuva, pois estas não correspondiam a condensação e sim precipitação. Foram realizadas classificações relativas à duração da condensação, como também estudo de casos. Para a análise dos casos específicos a condensação foi qualificada em três tipos de estágios de duração: de curta ( 1 - 5 horas); média (5 - 10 horas); longa (acima de 10 horas). Em todo o experimento foram observados 25 casos, sendo que no mês de setembro, fim do período seco, foram observadas 11 ocorrências, enquanto no período chuvoso foram detectados 14 casos, com 13 no mês de outubro e 1 em novembro. Quanto a sua qualificação, dos 25 casos estudados, 3 foram curtas, 7 médias e 15 longas.

\subsection{Variáveis calculadas}

Para a obtenção nos valores da temperatura do ponto de orvalho (Td), foi utilizada a equação a seguir:

$$
T d=\sqrt[8]{\frac{U R}{100}} *[112+(0,9 * T)]+(0,1 * T)-112
$$

onde $T$ é a temperatura do $\operatorname{ar}\left({ }^{\circ} \mathrm{C}\right)$ e o $U R$ é a umidade relativa do ar (\%).

\section{RESULTADOS E DISCUSSÃO}

\subsection{Comportamento da precipitação}

A Amazônia é predominantemente uma região de convergência atmosférica de umidade, onde prevalecem mecanismos de convergência na baixa troposfera. Ela é também conhecida como sumidouro de umidade, já que sua precipitação é conseqüência de sua própria evapotranspiração (Marengo et al. 2001) e fluxos de vapor d'água trazidos do Oceano Atlântico (Correia et al. 2007). As chuvas na região amazônica podem ser de origem convectiva, uma vez que os ventos são fracos e a movimentação do ar ocorre basicamente na vertical (Tucci 1997), produzindo processos de convecção, nuvens e chuvas. De acordo com Rocha (2001), a região amazônica apresenta uma grande variabilidade da precipitação no tempo e espaço associada à influência de diferentes sistemas de meso-escala (Complexos Convectivos), escala sinótica (Alta da Bolívia) e de grande escala (El Niño-Oscilação Sul (Drumond e Ambrizzi, 2003); Zona de Convergência do Atlântico Sul e Zona de Convergência Intertropical (Souza et al., 2000; Marengo et 
al., 2001). A marcha sazonal média da precipitação apresenta duas estações bem distintas, a estação de estiagem (inverno e primavera do HS), com precipitações inferiores a $100 \mathrm{~mm} \mathrm{mês}^{-1}$, e a estação chuvosa (verão e outono do HS) com precipitações superiores a $200 \mathrm{~mm} \mathrm{mês}^{-1}$.

Na segunda quinzena do mês de setembro, final do período seco, registrou-se o acumulado pluviométrico de 106,5 mm, correspondendo $34 \%$ do período estudado (Figura 1). Destaca-se que nos dias 28 e 29, do mesmo mês, concentraram-se em torno $70 \%$ desse total, com aproximadamente $70 \mathrm{~mm}$. Foi notado que somente no dia 16 ocorreu precipitação traço $(0,2 \mathrm{~mm})$, ou seja, precipitação com registros inferiores a $1 \mathrm{~mm}$, e em 9 dias não ocorreu precipitação. Já no mês de outubro, época em que ocorre o início do período chuvoso, a precipitação acumulada apresentou um aumento de $50 \%$ em relação ao mês anterior, onde os maiores índices ocorreram durante a tarde, com um total acumulado de $173,3 \mathrm{~mm}$ (55\% dos casos). Observou-se também, que em 11 dias foram registradas precipitações com valores superiores a $5 \mathrm{~mm}, 5$ dias com precipitações traços e 15 dias com estiagem. Segundo Santos (2005), a precipitação para o mês de outubro apresentou uma anomalia negativa em comparação à climatologia da região. Averigua-se que em novembro, até o dia 11, os índices pluviométricos acumulado foram de $33,3 \mathrm{~mm}$. Fazendo uma análise diária, verifica-se o acumulado de $15,8 \mathrm{~mm}$, no dia 04 , e dois dias com precipitações traços (dias 5 e 7 com os respectivos valores de $0,4 \mathrm{~mm}$ e $0,1 \mathrm{~mm}$ ). Ressalta-se que nesse mesmo mês obteve-se 5 dias sem registro de precipitação.

A Figura 2a mostra a distribuição da soma horária das precipitações durante todo o experimento, onde a precipitação total acumulada no período foi de $313,1 \mathrm{~mm}$, com $84 \%$ dos casos no período diurno (07:00 - 18:00 HL) e 16\% no noturno (19:00 - 06:00 HL). Especificamente, no período diurno, as máximas se concentraram no período da tarde (13:00 às 17:00 HL), o que é característico da região, com cerca de $79 \%$ dos casos observados $(247 \mathrm{~mm})$. Isto pode estar relacionado ao aquecimento ocasionado pela radiação durante o dia, o que acarreta instabilidade próxima à superfície, que conjuntamente com a grande quantidade de umidade presente na região, formam nuvens convectivas e, conseqüentemente, a ocorrência de chuva no período da tarde e/ou início da noite (Mota 2007).

A distribuição horária de precipitação nos períodos seco e chuvoso, é semelhante (Figura 2 b), às das chuvas concentradas no período da tarde, sendo $64,4 \%$ dos casos nos períodos seco e $86 \%$ no chuvoso. Ferreira da Costa (1998) constatou que as concentrações das precipitações durante a tarde na Amazônia ocorrem, provavelmente, em decorrência do aquecimento repentino na pastagem, facilitando o desenvolvimento da nebulosidade, que atinge a maturação em um espaço de tempo menor, fazendo com que haja precipitação no início da tarde. Independentemente da época, as precipitações ocorrem no período vespertino, que conforme já explicado anteriormente, são de origem convectiva, mas durante o período chuvoso elas são influenciadas por sistemas frontais, que se deslocam da região sul do Brasil até sul da Amazônia.

\subsection{Influências das variáveis meteorológicas na condensação}

\subsubsection{Influência da condensação nos sensores WSG237}

Durante a condensação, o sensor WSG237 1 apresentou resistências médias entre $3435 \Omega$ e $4059 \Omega$, enquanto o WSG237_2 médias de $3204 \Omega$ e $3903 \Omega$, respectivamente (Figura 3). Especificamente, durante a madrugada, na qual é comum ocorrer condensação a superfície, no período seco observaram-se médias de $429 \Omega$ e $166 \Omega$ e no período chuvoso notaram-se médias de $1930 \Omega$ e $1618 \Omega$. Durante este último período as médias das resistências se mantiveram altas devido à eliminação dos dados nas horas em que foram registradas as precipitações. Nas primeiras horas da manhã ( \pm 06:00 às 08:00 HL), no período seco, a resistência do WSG237_2 apresentou um forte crescimento de $189 \Omega$ para $5407 \Omega$, e no chuvoso de $1722 \Omega$ para $5681 \Omega$ (Figura 3a). $\mathrm{O}$ forte aumento da resistência está relacionado

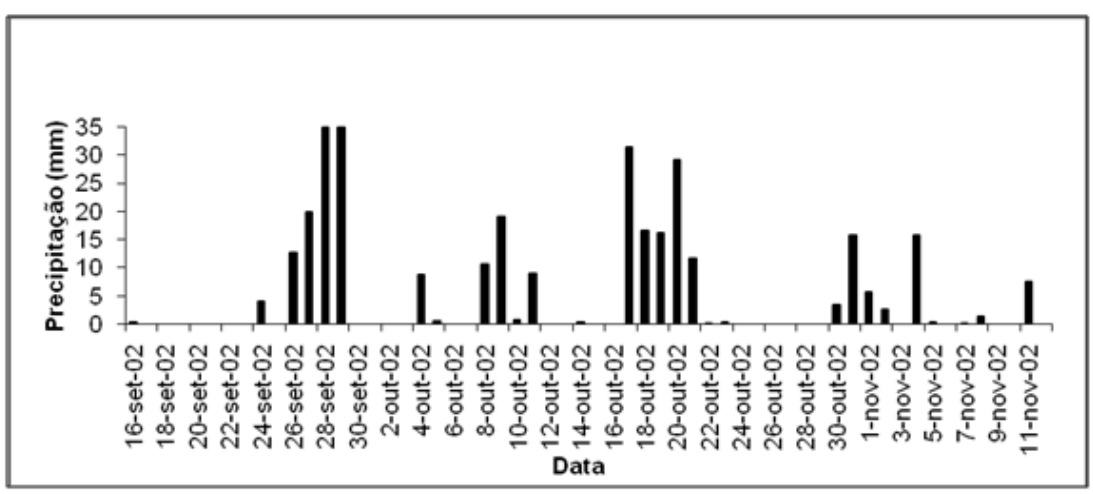

Figura 1- Distribuição do total diário da precipitação durante o experimento. 

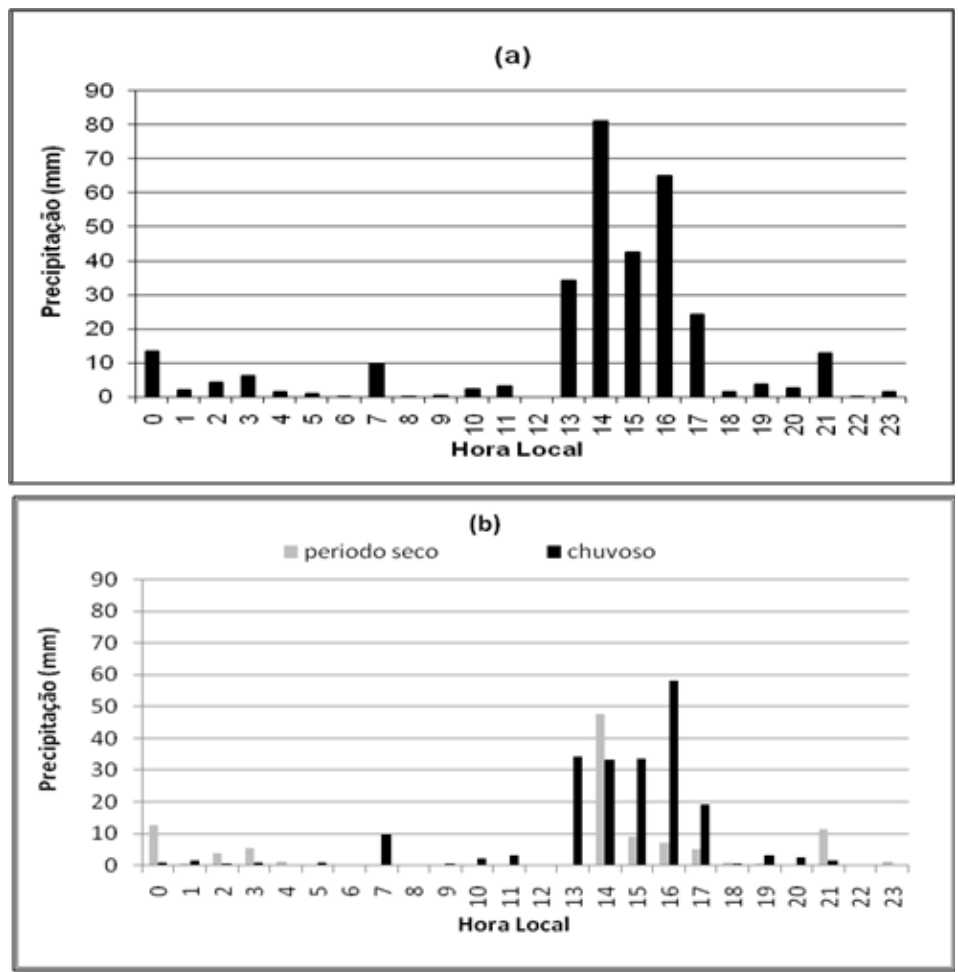

Figura 2 - Distribuição do total horário acumulado durante todo o período experimental (a) e durante os períodos: seco (16 a 30/set) e chuvoso (01/out a $12 /$ nov) (b).

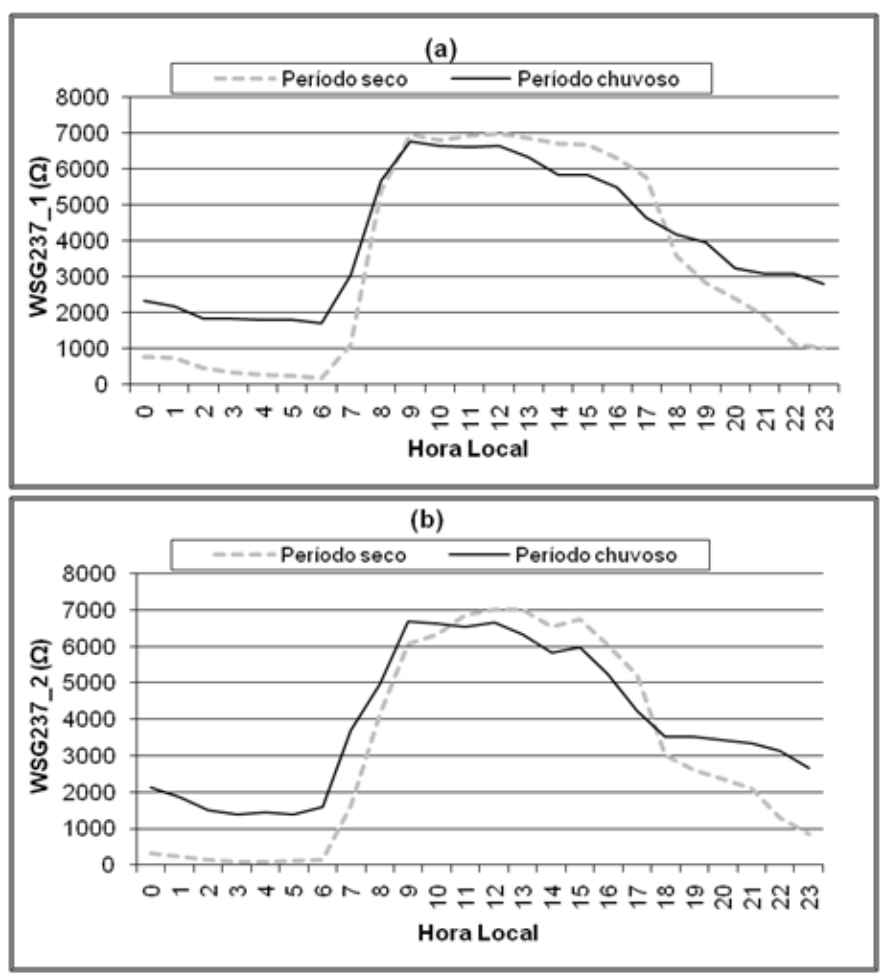

Figura 3 - Registro médio das resistências do WSG237_1 (a) e WSG237_2 (b) nos períodos seco e chuvoso durante no experimento. 
ao aquecimento solar que faz com que a umidade contida no sensor seja evaporada, uma vez que o mesmo está instalado na parte superior (acima) da vegetação. No sensor WSG237_1, sua resistência média oscilou de $154 \Omega$ a $4148 \Omega$ no período seco, e $1600 \Omega$ a $4978 \Omega$ no período chuvoso (Figura $3 b$ ). Essa menor variação se dá devido ao armazenamento de umidade entre as folhagens, que nos primeiros momentos do sol atuou como uma barreira contra fatores externos, sombreando o sensor e retardando assim a evaporação da água condensada sobre o mesmo. A partir das 09:00 HL até o anoitecer os sensores se apresentaram absolutamente secos. Ao anoitecer a resistência volta a apresentar quedas significativas no período seco com valores médios de 2089 $\Omega$, enquanto no período chuvoso as médias ficaram superiores a $3260 \Omega$ em ambos os sensores. Estas quedas estão relacionadas à estabilidade térmica com surgimento de inversão de temperatura do ar próxima ao solo nas primeiras horas da noite.

\subsection{Estudo de casos}

A condensação ocorre quando a água é evaporada e se eleva sobre o solo, então ela tende a atingir um nível, cuja temperatura da parcela (ou seja, da água evaporada) é inferior a temperatura ambiente, ocorrendo assim a condensação, isto é, a formação de gotículas. Esse parâmetro climático importante na Amazônia é a chamada "precipitação oculta", resultado da intensa condensação noturna, especialmente nos meses mais frios, que ocorre quando a temperatura do ar (Tar) real se iguala à temperatura de ponto de orvalho (Td). Na Amazônia, é comum observar-se nevoeiros durante a madrugada, principalmente na época seca, quando as temperaturas mínimas são mais baixas, como foi observado por Bastable et al. (1993); Silva e Lyra (1996) e Souza (1997). Segundo Silva (2004) existem três formas de se alcançar a saturação: (1) decréscimo de temperatura, reduzindo assim a capacidade do ar atmosférico em reter água em forma de vapor, (2) aumentando à quantidade de vapor d'água presente no ar, (3) reduzindo a temperatura e, paralelamente, aumentado a quantidade de vapor. Para quantificar o numero de ocorrência desse fenômeno, selecionaram-se alguns casos com base nesse critério adotado por Silva e Lyra (1996), segundo os quais ocorre a formação de nevoeiro quando a umidade relativa do ar (UR) é igual ou superior a $96 \%$ (UR $\geq 96 \%$ ). Salienta-se que pesquisas realizadas por Galvão (1999), para esta mesma região de estudo, registraram a ocorrência de nevoeiros foi com UR da ordem de $81 \%$.

\subsubsection{Evento dos dias 02 e 03 de outubro de 2002 (curta duração)}

Um breve caso de condensação foi observado no dia 03 , aproximadamente entre 01:00 e 07:00 HL. Durante este dia não foi detectado nenhuma ocorrência de precipitação (Figura 4a). Às 20:00 e 21:00 HL o WSG237_1 aponta uma súbita queda de sua resistências devido ao acúmulo de umidade armazenada entre as folhagens. Entre 22:45 e 00:15 HL as resistências apresentaram uma ligeira queda, em decorrência de um aumento repentino da UR e redução da Tar. No início da condensação, a partir da 01:00 HL, as resistências dos sensores têm uma forte queda que coincide com a diminuição da intensidade do vento e aumento da UR.

Durante o dia as temperaturas do ar e do solo ficaram acima dos $33{ }^{\circ} \mathrm{C}$ e $31{ }^{\circ} \mathrm{C}$, enquanto a umidade relativa do ar (UR) era inferior a 50\% (Figura 4b), não proporcionando a ocorrência de condensação e ocasionando alta resistência do WSG237 (Figura 4a). Neste mesmo período houve aumento da nebulosidade ocasionando grandes oscilações no saldo de radiação $(\mathrm{Rn})$ por conta da variabilidade no comportamento do vento, apresentando valores próximo à $3,0 \mathrm{~m} \mathrm{~s}^{-1}$. Nos horários de 17:00 e 18:00 HL, aproximadamente, a temperatura do ar e a UR tiveram bruscas variações, correlacionadas com um forte resfriamento superficial. No período noturno, principalmente às 20:00 HL, ocorre aumento da Tar e queda da UR, associado ao aumento da intensidade do vento. Após às 22:00 HL a Tar volta a diminuir e a UR registra aumento, ultrapassando os $80 \%$. Entre 23:00 e 00:00 HL, com um novo aumento da velocidade do vento, a Tar e a UR apresentam pequenas oscilações. No início da madrugada ocorre a calmaria do vento, o que proporciona juntamente com elevada UR e baixa Tar o início do processo de condensação. Possivelmente, um dos fatores que fizeram com que as resistências do WSG237 se estabilizassem foi à proximidade da Tar com a temperatura do ponto de orvalho (Td) juntamente com a alta UR. A manutenção da condensação, até aproximadamente às 08:00 $\mathrm{HL}$, ocorreu pelas baixas temperaturas, altos índices de umidade e pelo maior saldo negativo de ondas longas. É importante ressaltar que mesmo o vento apresentando oscilações de até $1,5 \mathrm{~m} \mathrm{~s}^{-1}$ (Figura 4c), o processo de condensação se manteve. Observou-se que a condensação (precipitação oculta) se dissipou completamente por volta das 07:00 HL.

\subsubsection{Evento dos dias 06 e 07 de outubro de 2002 (média duração)}

Aproximadamente às 15:00 $\mathrm{HL}$ se inicia mais intensamente o processo de resfriamento, pois o Rn, velocidade do vento e Tar começam a decrescer e a UR aumentar (Figura 5a), mesmo assim, essa não foi à condição suficiente para o início da condensação. Às 17:00 HL o Rn e velocidade do vento são nulos (Figura 5c), ou seja, forte resfriamento através da emissão de onda longa, e calmaria total. Isso faz com que a Tar diminua mais intensamente da mesma forma que a UR 
aumenta. Por volta das 19:00 HL a condição ideal para o início da condensação é alcançada, ou seja, UR acima de $90 \%$ e Tar abaixo de $25^{\circ} \mathrm{C}$. Pode-se observar que do inicio ao término da condensação, esta nunca foi máxima, uma vez que as resistências registradas nunca atingiram o valor zero. É provável que este fato esteja relacionado às pequenas oscilações apresentadas pelo vento (Figura 5c), o que proporciona pequenas misturas turbulentas do ar próximo a superfície, fazendo com que a condensação não seja plena, mesmo tendo UR atingindo o valor de 95,5\%. Observa-se que os valores da Tar estão próximos da $\mathrm{Td}$, condição esta, que se mantém até o início da madrugada. A partir das 22:00 HL, devido a relativa calmaria e a proximidade entre as duas temperaturas tem-se as condições para que ocorra a formação de nevoeiro. As Tar a Td apresentaram algumas variações durante a madrugada, ocasionada pela variação na intensidade dos ventos. Ressalta-se que durante o dia houve uma expressiva nebulosidade, o que refletiu no registro de $\mathrm{Rn}$ que apresentou grande oscilação (Figura 5c).

No dia 7 com o nascer do sol sem nebulosidade, Rn não apresentou oscilações, algo semelhante ocorreu na tarde do dia anterior, o que permite inferir-se que todo período noturno foi de céu claro. Com isso o processo de evaporação da água condensada foi iniciado com o nascer do sol (aproximadamente às 06:00 HL).
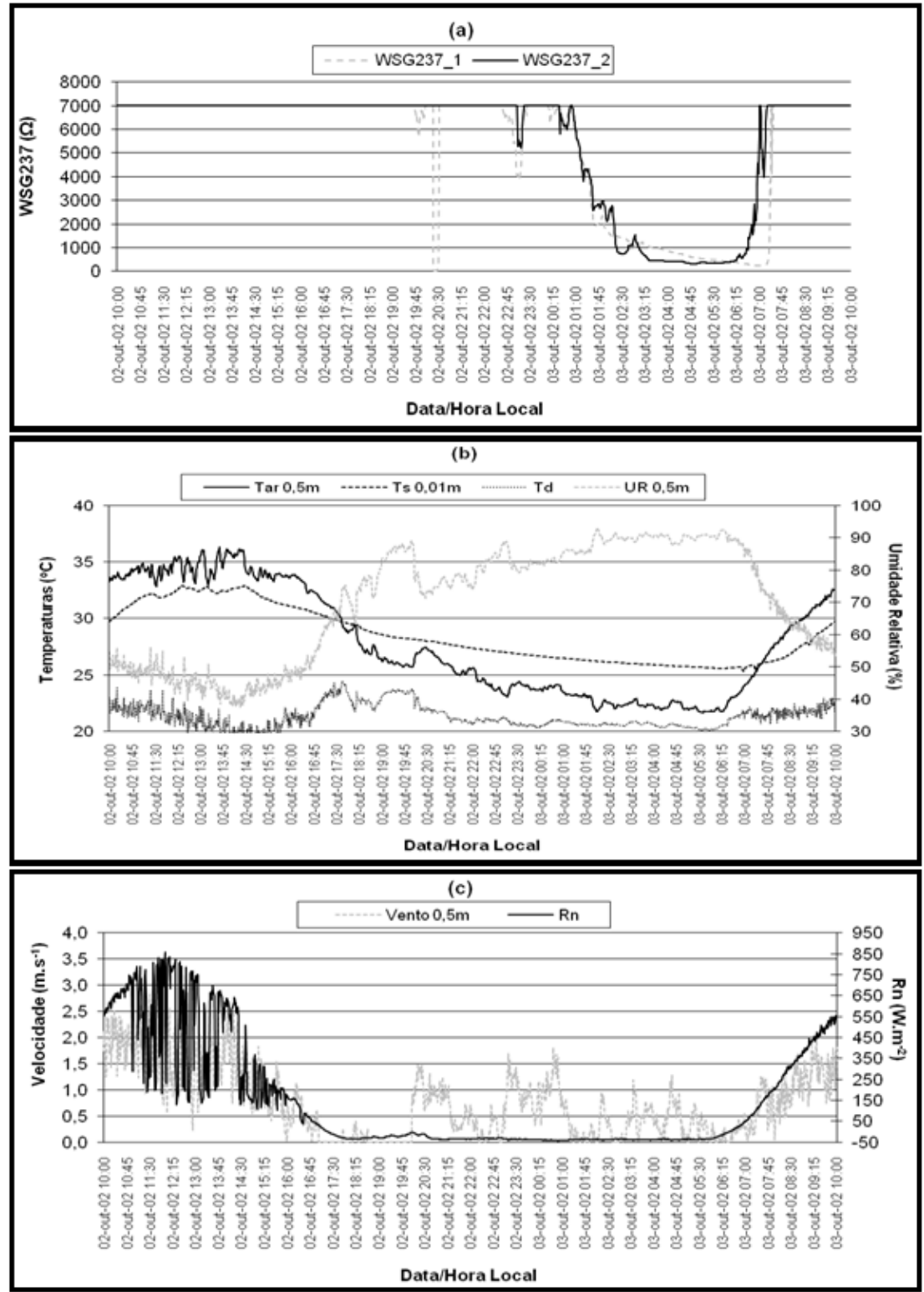

Figura 4 - Registros das resistências do WSG237_1 e 2 (a), temperatura do ar (Tar), do solo (Ts) e do ponto de orvalho (Td) e umidade relativa do ar (UR) (b) velocidade do vento e saldo de radiação (Rn) (c). 


\subsubsection{Evento dos dias 28 e 29 de outubro de 2002 (longa duração)}

Após às 16:00 HL, foi observado queda na resistência dos WSG237_2 (Figura 6a) que foi originada pelas quedas nas temperaturas do ar e do solo (Figura 6b), no Rn e na intensidade dos ventos (Figura 6c) e no aumento da UR, no que acarretou o início da condensação, ainda que a UR registrasse valores abaixo de 65\%. Às 17:30 HL os sensores detectam a formação da condensação, proporcionado pelo aumento da UR e decréscimo nos valores do Rn, velocidade do vento e Tar. A partir das 16:45 HL o WSG237_2 registrou resistência próxima a zero. Às 19:00 HL à intensidade dos ventos apresentou oscilações de até 3,5 $\mathrm{m} \mathrm{s}^{-1}$, que conduziu a pequenas misturas turbulentas, aumento da Tar e das resistências do WSG237 e queda rápida na UR.
Próximo às 20:00 HL, a UR apresenta valores superiores a $80 \%$, enquanto que a Tar apresentava queda, fazendo com que os registros das resistências também diminuíssem. Ao longo da noite o registro da UR foi superior à $82 \%$, Tar com valores inferiores à $25{ }^{\circ} \mathrm{C}$ e forte resfriamento superficial. Durante a condensação as resistências do WSG237 são baixas e o Rn igual à zero, mas a Tar obtém médias relativamente altas, pelo fato de que na pastagem ocorre maior retorno de energia para a atmosfera, na forma de calor sensível. Por volta das 22:00 HL, se observa baixa intensidade dos ventos (inferiores a $0,5 \mathrm{~m} \mathrm{~s}^{-1}$ ), e pequena queda no valor médio de Tar (inferior à $25^{\circ} \mathrm{C}$ ) seguido de aumento da UR (próximo de 90\%), situação que se estende durante toda a madrugada, o que proporcionou a formação de nevoeiro a partir da 00:00 HL, durando até ao amanhecer. É importante citar que as quedas bruscas no Rn (Figura 6c), a

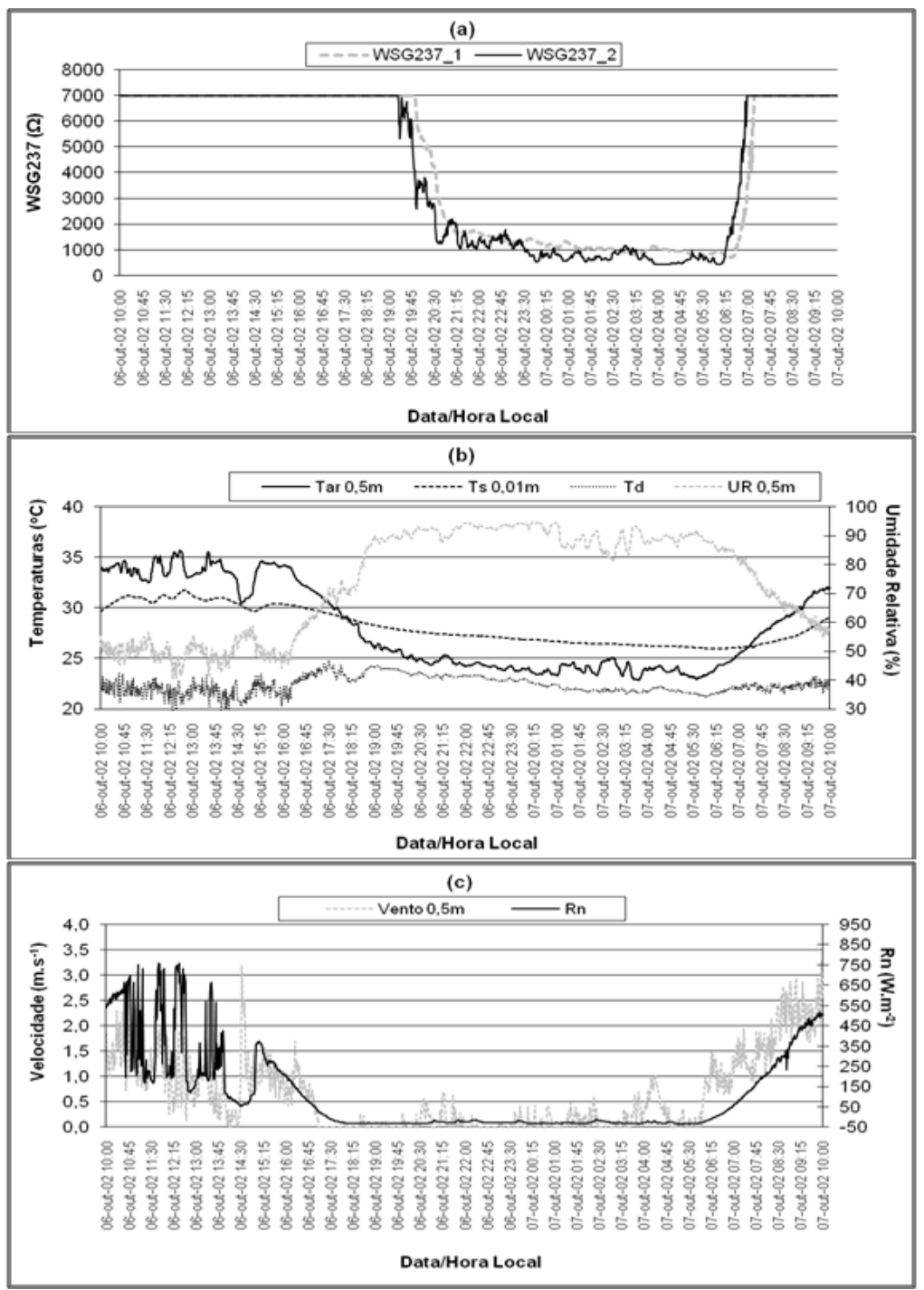

Figura 5 - Registros das resistências do WSG237_1 e 2 (a), temperatura do ar (Tar), do solo (Ts) e do ponto de orvalho (Td) e umidade relativa (UR) do ar (b) velocidade do vento e saldo de radiação (Rn) (c). 


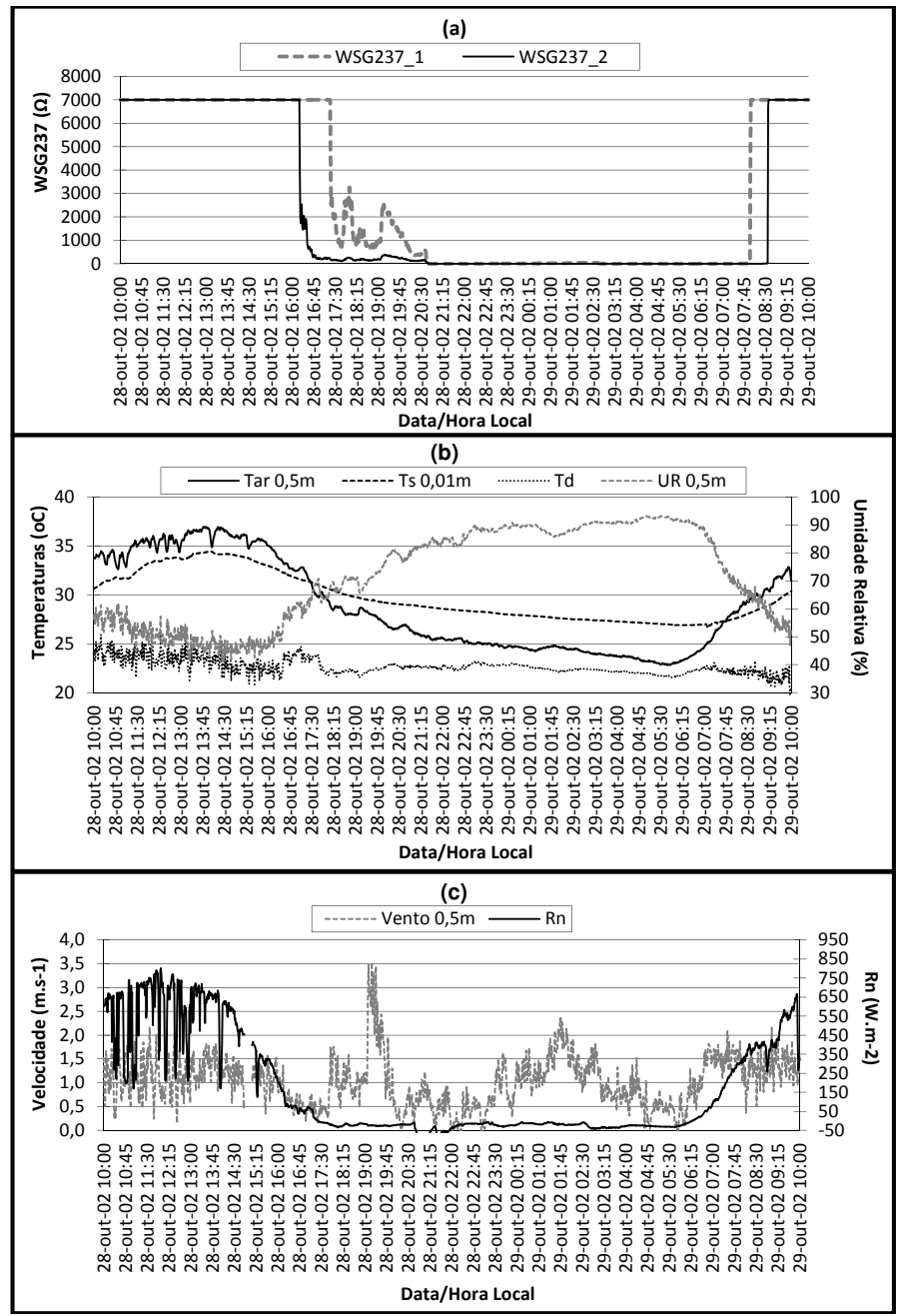

Figura 6 - Registros das resistências do WSG237_1 e 2 (a), temperatura do ar (Tar) e do solo (Ts) e do ponto de orvalho (Td) e umidade relativa do ar (UR) (b) velocidade do vento e saldo de radiação (Rn) (c).

partir das 12:00 HL, estão provavelmente associadas a presença de nebulosidade, que também acarretou uma ligeira variação nas temperaturas do ar e do solo (Figura 6b).

Com o aparecimento do sol ao amanhecer, foi observado queda significativa da UR e, conseqüentemente, aumento da Tar, Td, Ts e Rn. Próximo às 08:00 HL o WSG237 inicia aumento de suas resistências, ocasionado pela evaporação da água condensada que se encontrava presente nos sensores.

\section{CONCLUSÕES}

Apesar das condições estabelecidas durante as análises não serem garantia de que ocorra condensação, é possível registrar-se as seguintes conclusões: 1- tanto no período seco como chuvoso as chuvas se concentraram no período vespertino, aproximadamente entre 13:00 e 17:00 HL, formando condições ideais para a condensação através da intensificação do resfriamento; 2- as condições propícias para sua formação foram iniciadas entre 16:00 - 18:00 HL, intensificando-se durante o período noturno por conta do resfriamento do ar junto a superficie; 3- entre os períodos analisados não se observou diferenças nos processos da condensação. Quanto à origem da condensação, foi notado que houve semelhanças nos valores das variáveis meteorológicas nos períodos seco e chuvoso; 4- em termos médios sua origem se deve a baixa intensidade do vento (inferior a $1,5 \mathrm{~m} \mathrm{~s}^{-1}$ ), alta umidade relativa do ar (UR superior a $80 \%$ ), Temperatura do ar (Tar inferior a $25^{\circ} \mathrm{C}$ ), intenso resfriamento superficial, com Rn de aproximadamente $-24 \mathrm{~W}$ $\mathrm{m}^{-2}$ e Temperatura do solo $(\mathrm{Ts})(0,01 \mathrm{~m})$ de aproximadamente $26^{\circ} \mathrm{C}$; 5- no máximo em uma hora e meia após o nascer do sol ocorreu a dissipação (evaporação) completa de toda condensação acumulada na superfície; 6- quanto a sua duração, as longas obtiveram médias de 12 horas, mas houve um caso isolado de 17 horas, enquanto que as de média duração foram de 7 horas e 
as de curta duração foram em torno de 3-4 horas, em razão da intensidade dos ventos que retardaram sua formação; 7- quanto aos eventos específicos verificou-se que o aumento da velocidade do vento (acima de 1,0 $\mathrm{m} \mathrm{s}^{-1}$ ) provocou oscilações nas resistências do sensor de condensação (WSG237).

\section{REFERÊNCIAS BIBLIOGRÁFICAS}

ANDREAE, M. O. et al. Towards an understanding of the biogeochemical cycling of carbon, water, energy, trace gases, and aerosols in Amazonia: The LBA-EUSTACH experiments, Journal Geophysical Research. v. 107, n. D20, 8066-8091, 2002.

ARTAXO, P. et al. Efeitos climáticos de partículas de aerossóis biogênicos e emitidos em queimadas na Amazônia. Revista Brasileira de Meteorologia, v.21, n.3, p. 1-22, 2006.

BASTABLE, H. G.; SHUTTLEWORTH, W. J.; DALLAROSA, R. L. G.; FISCH, G.; NOBRE, C. A. Observation of climate, albedo and surface radiation over cleared and undisturbed Amazonian forest. International Journal of Climatology, v. 13, n. 7, p. 783-796, 1993.

CORREIA, F. W. S.; MANZI, A. O.; CANDIDO, L. A.; SANTOS, R. M. N.; PAULIQUEVIS, T. Balanço de umidade na Amazônia e sua sensibilidade às mudanças na cobertura vegetal. Ciência e Cultura (SBPC), v. 59, p. $39-43,2007$.

CUTRIM, E.; MARTIN, D. W.; RABIN, R. Enhancement of cumulus clouds over deforested lands in Amazonia. Bulletin of the American Meteorological Society, v.76, n. 10, p.1801-1805, 1995.

DIAS, M. A. F. S.; REGNIER, P. Simulation of mesoscale circulation in a deforested area of Rondônia in the dry season. Amazonian deforestation and climate. Chichester: John Wiley, p. 531-547, 1996.

DRUMOND, A. R. M.; AMBRIZZI, T. Estudo observacional e numérico da variação da circulação atmosférica nas Américas em episódios extremos da Oscilação Sul. Revista Brasileira de Meteorologia. v. 18, n. 1, p. 1-12, 2003.

FERREIRA DA COSTA, R.; FEITOSA, J. R. P.; FISCH, G.; SOUZA, S. S.; NOBRE, C. A. Variabilidade diária da precipitação em regiões de floresta e pastagem na Amazônia. Acta Amazônica, v. 28, n. 4, p. 395-408, 1998.

GALVÃO, J. A. C. Estudo do balanço de radiação em áreas de floresta e pastagem na Amazônia. Dissertação (Mestrado em Meteorologia). Instituto Nacional de Pesquisas Espaciais. 125 p. 1999.

GASH, J. H. C.; NOBRE, C. A.; Climatic effects of Amazonian deforestation: some results from ABRACOS. Bulletin of the American Meteorological Society, v.78, n.5, p.823830, 1997.
KIRKMAN, G. A. et al. Surface exchanger of nitric oxide, nitrogen dioxide and ozone at a cattle pasture in Rondonia, Brazil. Journal Geophysical Research, v. 107, n. D20, p. 51-68, 2002.

MARENGO, J. A. et al. Onset and end of the rainy season in the Brazilian Amazon Basin. Journal Climate, v. 14, n.3, p.833-852, 2001.

MARTINS, J. A.; Efeitos da turbulência no crescimento de gotículas por condensação de vapor d'água em nuvens. Dissertação (Mestrado em Meteorologia). Instituto Nacional de Pesquisas Espaciais. 128p, 1999.

MOTA, M. A. S. Convecção na Amazônia: variabilidade, efeitos e resposta na circulação de grande escala. Tese (Doutorado em Meteorologia). Instituto Nacional de Pesquisas Espaciais, São José dos Campos. 194p. 2007.

ROCHA, E. J. P. Balanço de umidade e influência de condições de contorno superficiais sobre a precipitação da Amazônia. Tese (Doutorado em Meteorologia). Instituto Nacional de Pesquisas Espaciais, São José dos Campos. 210p. 2001.

SANTOS, L. A. R. Análise e caracterização da camada limite convectiva em área de pastagem, durante o período de transição entre a estação seca e chuvosa na Amazônia (Experimento RACCI-LBA/Rondônia). Dissertação (Mestrado em Meteorologia). Instituto Nacional de Pesquisas Espaciais, São José dos Campos. 118p. 2005.

SILVA, M. R. G.; LYRA, R. Efeitos do desmatamento na termodinâmica da camada limite noturna: Projeto RBLE. In: Congresso Brasileiro de Meteorologia, 9., Campos do Jordão. Anais. Campos do Jordão: Sociedade Brasileira de Meteorologia, v. 2, p. 1229-1232. 1996.

SILVA, M. R. G. Aspectos da termodinâmica da camada limite atmosférica no oeste da Amazônia durante a estação chuvosa - experimento WET AMC/LBA. Dissertação (Mestrado em Meteorologia). Universidade Federal de Alagoas, Maceió. 80p. 2004.

SOUZA, S. S. A substituição da floresta Amazônica por pastagem e sua repercussão ao nível da termodinâmica da camada limite atmosférica: Projeto RBLE. Dissertação (Mestrado em Meteorologia). Campina Grande, Universidade Federal da Paraíba. 110p. 1997.

SOUZA, E. B. et al. On the Influences of the El Niño, La Niña and Atlantic dipole pattern on the Amazonian Rainfall during 1960-1998. Acta Amazonica, v. 30, n. 2, p. 305-318. 2000.

TREBS, I. et al. Real-time measurements of ammonia, acidic trace gases and water-soluble inorganic aerosol species at a rural site in the Amazon Basin, Atmospheric Chemistry and Physics, v. 3, n. 4, p. 967-987, 2004.

TUCCI, C. E. M. Hidrologia: Ciência e Aplicação. Editora da Universidade/ABRH, Porto Alegre - RS, Brasil. 450p, 1997. 